\title{
UBC takes over Therapeutics Initiative after provincial cuts
}

$\mathrm{S}$ ix months after British Columbia's Liberal government quietly suspended funding to the province's leading independent pharmaceutical safety research group, officials at the University of British Columbia (UBC) in Vancouver have stepped in.

UBC agreed to finance the Therapeutics Initiative, which has published independent drug safety and efficacy assessments for 19 years, after the province reneged on a long-standing agreement to provide the university with $\$ 550000$ annually for the research group, which is primarily staffed by UBC personnel. That deal was to have continued until 2015.

"The university has decided it will protect the integrity of the Therapeutics Initiative," Lucie McNeill, UBC's public affairs director, told CMAJ. "Because once you disband a unit like this, it is very hard to put it back together again."

In September, the BC Ministry of Health told the Therapeutics Initiative in a letter to suspend its activities pending the outcome of a government investigation into the handling of drug data by ministry employees. That investigation resulted in the firing and suspension of seven scientists and officials last summer - none of them Therapeutics Initiative staff.

All seven have since started legal actions claiming the government tried to kneecap independent drug safety research while inflicting severe per- sonal and professional harm long before it completed the investigation.

In October, the ministry suspended payments for the initiative, but declined to comment on its decision. Spokesperson Ryan Jabs referred instead to Health Minister Margaret MacDiarmid's statement that the government had handed its investigation into allegations of inappropriate conduct, contracting and datamanagement practices involving former ministry employees, researchers and contractors to the Royal Canadian Mounted Police. Although the ministry seems to be linking its investigation to its decision to stop funding the Therapeutics Initiative, the research group has not been singled out during that investigation itself, McNeill notes.

"This [investigation] has focused on personnel both internal and external to the ministry, some of whom also have UBC connections. But it is not the [Therapeutics Initiative] itself that is the focus of the investigation," she says.

The Therapeutics Initiative promotes drug safety and provides substantial benefits to patients and clinicians, McNeill says. The initiative's research has led to changes in the way $95 \%$ of physicians and $92 \%$ of pharmacists in the province say they prescribe or recommend drugs, according to the research group's own survey.

During the May 14 provincial election, BC New Democratic Party (NDP)

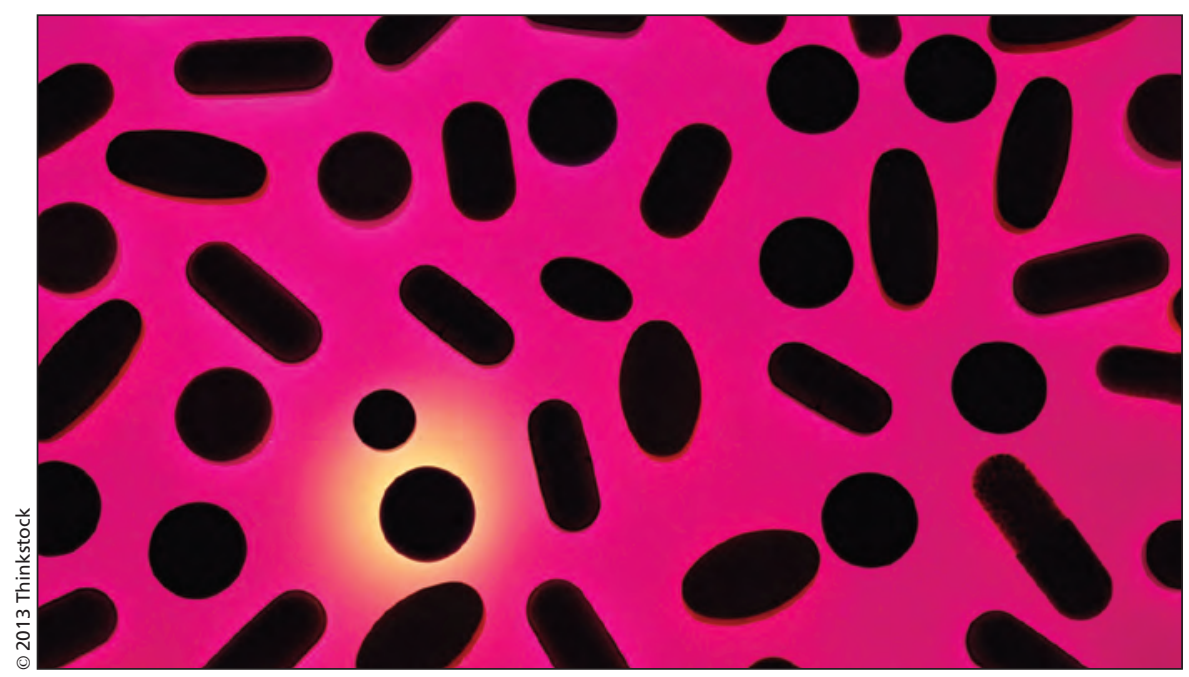

The Therapeutics Initiative, which has published independent drug safety and efficacy assessments for 19 years, has led to changes in the way $95 \%$ of physicians and $92 \%$ of pharmacists in BC prescribe or recommend drugs.
Leader Adrian Dix publicly rebuked the Liberal government for stopping its funding. The NDP pledged that, if elected, it would "restore the Therapeutic Initiative's role as BC's drug watchdog and make its expertise available to private drug plans, clinicians and consumers."

Dix recently praised the initiative for saving lives and more than $\$ 100$ million annually in pharmaceutical costs for the province. The initiative frequently raised early concerns about the safety of drugs that government regulators later reinforced, Dix says.

The incumbant Liberals, under Premier Christy Clark won the $\mathrm{BC}$ election.

Even before it stopped funding the initiative, the ministry blocked researchers with the UBC-based group from accessing data in PharmaNet. The provincial database is widely considered to be North America's best repository of such data, containing comprehensive information from patients, clinicians and pharmacists throughout BC.

Taken together, the denial of data and funding to the initiative amounts to a government attack on "important research into drug safety," says Colin Dormuth, a researcher with the initiative. He and his colleagues are deeply frustrated by the government's actions, he says.

The ministry's decision to block researchers with the initiative from PharmaNet is inexplicable, says Jim Wright, the research group's codirector. Since the province suspended its funding in October, it has "left us in a very precarious situation and we are extremely relieved that the university has agreed to support us for a few months more."

To help ease the financial pressure, Wright and two other officials (all three of whom earn salaries elsewhere) have agreed to waive the honoraria the initiative was paying them.

"The key goal for us is to make sure people with the initiative don't lose their appointments," says Wright. "I intend to stay on and get the initiative back to a fully funded situation. We need our data access restored and we need our funding back." - Paul Christopher Webster, Toronto, Ont.

CMAJ 2013. DOI:10.1503/cmaj.109-4485 